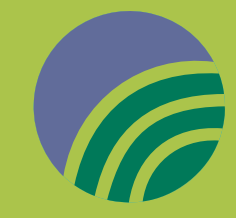

\title{
MRS helps bolster materials education in Italy and increase interactions with academia
}

\author{
By Lori A. Wilson
}

Tn early October 2017, the first meetof Materials Scientists" took place at the Center for Nanotechnology Innovation (CNI) in Pisa, Italy. The initiative originated with Valerio Voliani, a researcher at one of the national centers of the Istituto Italiano di Tecnologia (IIT). The institute was created with the objective of promoting Italy's technological development and higher education in science and technology.

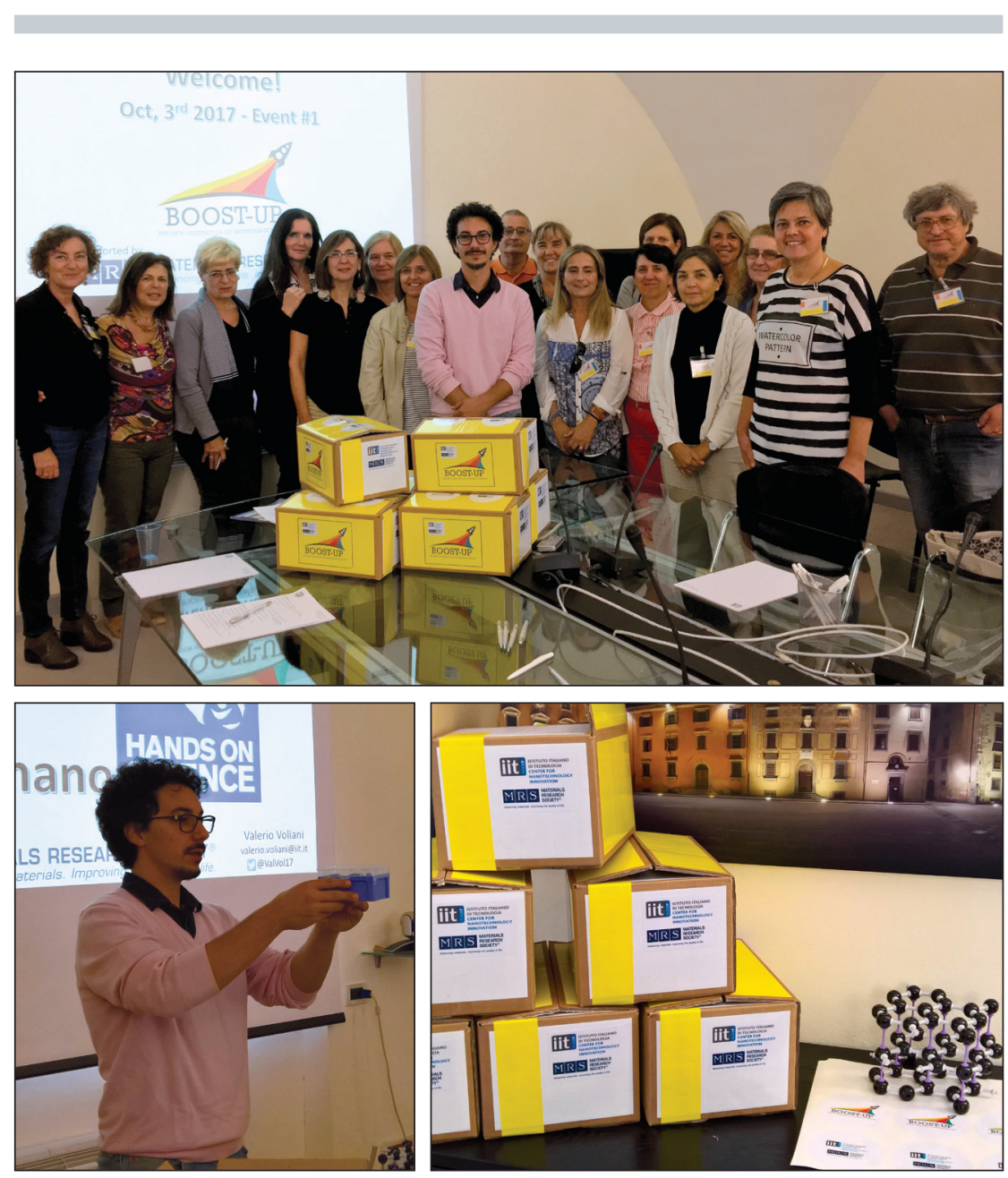

Top: Valerio Voliani (center) with a group of educators on the first day of the Boost-Up workshop in Pisa, Italy. Bottom right: One of the educational kits used during the first day of the Boost-Up workshop. Credits: A. Russo, Istituto Italiano di Tecnologia.
Voliani aims to transfer the latest materials research results and tools to the next generation. Undergraduate students and high-school teachers in Pisa ferent activities. The first strives to allow researchers and teachers to work more closely together by exchanging knowledge on advanced materials science. The second permits students to work directly in research laboratories. and Livorno were involved in two dif- 
science research. In particular, they will visit the laboratory, use transmission electron microscopy to observe the nanoparticles they have synthesized using the experimental kits, observe cells using confocal microscopy, observe the synthesis of chemical vapor deposition grown graphene and its characterization by Raman spectroscopy and atomic force microscopy, and employ recombinant DNA technology for protein production.

IIT hopes to increase the interaction between academia and local high schools; recognize and support future-generation scientists; and improve the knowledge of materials science educators. In Italy, science education in the public school system - in particular, materials science - is under-taught and poorly perceived. As a result, instructors with an out-of-date education are teaching these subjects, causing both disorder in the educational system and the loss of promising students, as they choose not to continue academic coursework in scientific fields or even in academia. By educating the teachers on novel materials (nanostructures and $2 \mathrm{D}$ materials), they may then pass this

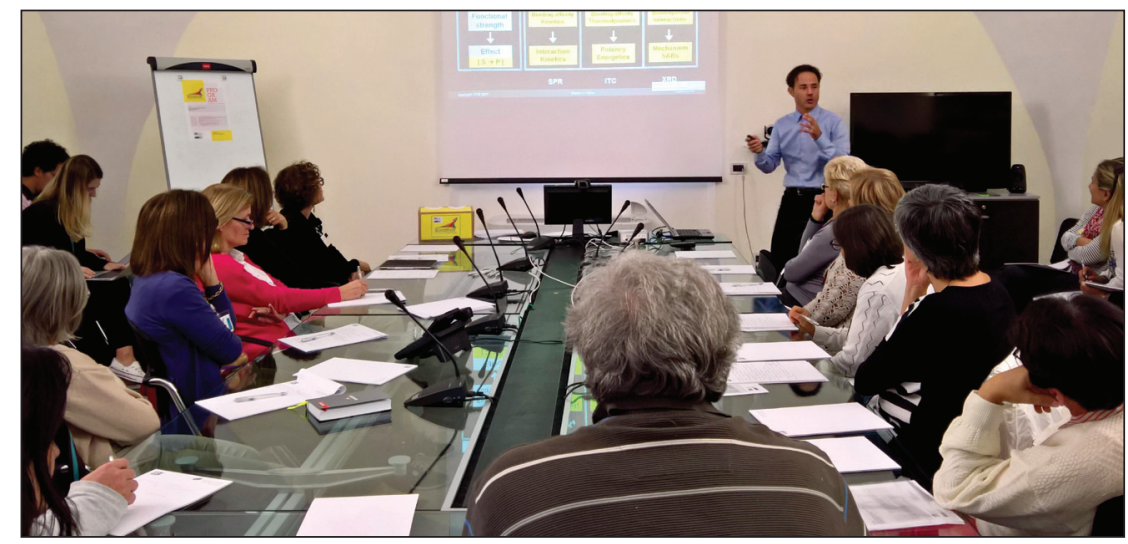

Gianpiero Garau, Istituto Italiano di Technologia (IIT) team leader, presenting information to the teachers at the Boost-Up workshop. Credit: A. Russo, IIT.

information onto their students, and these students can strengthen and improve their problem-solving and critical-thinking skills. "I hope this project will improve the perception of science in the next generation. Maybe we will boost-up new materials scientists!" said Voliani.

Through the Boost-Up program and the MRS grant, the goal is to have a longterm collaboration between local high schools in Italy and academia, which will attract students to scientific subjects and raise awareness of novel materials.

The Materials Research Society Foundation supports grassroots grants to allow initiatives that broaden the impact within and outside of the materials community.

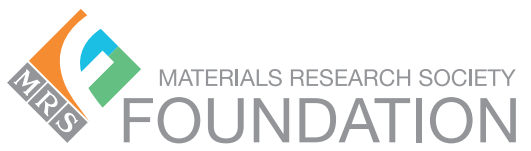

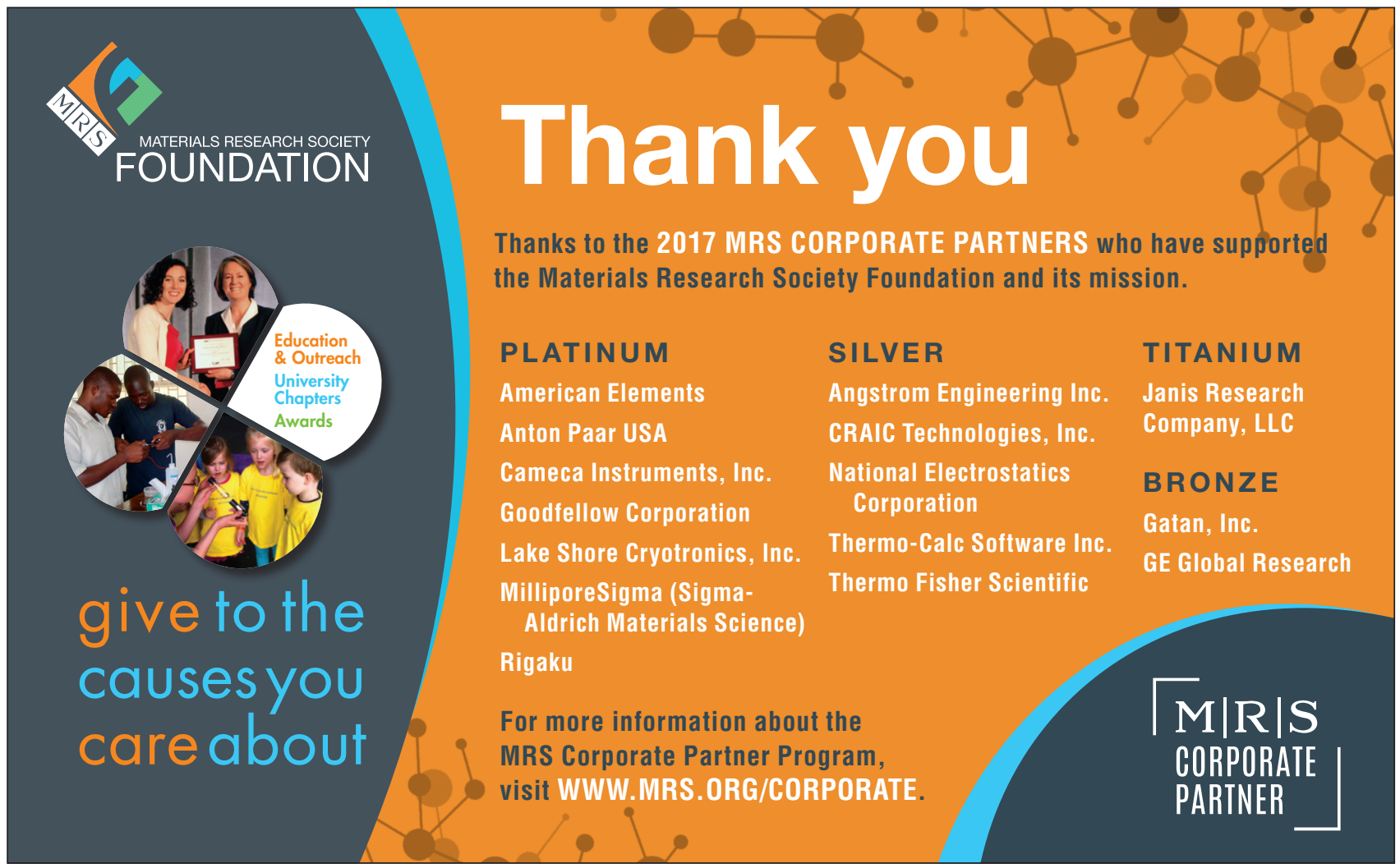

